\title{
Advanced Small Modular Reactor Economics Status Report
}

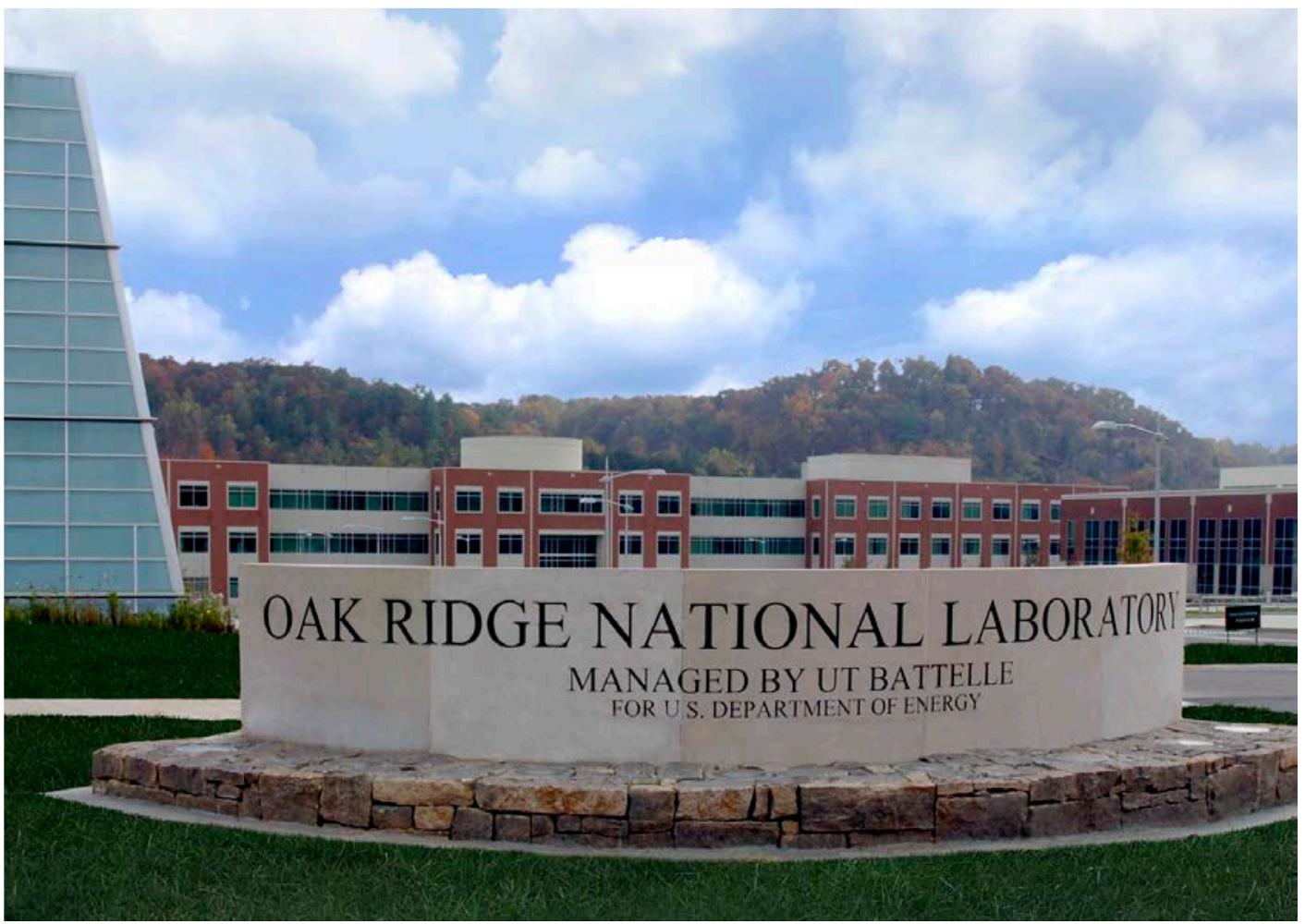

Approved for public release; distribution is unlimited. 
This report was prepared as an account of work sponsored by an agency of the United States Government. Neither the United States Government nor any agency thereof, nor any of their employees, makes any warranty, express or implied, or assumes any legal liability or responsibility for the accuracy, completeness, or usefulness of any information, apparatus, product, or process disclosed, or represents that its use would not infringe privately owned rights. Reference herein to any specific commercial product, process, or service by trade name, trademark, manufacturer, or otherwise, does not necessarily constitute or imply its endorsement, recommendation, or favoring by the United States Government or any agency thereof. The views and opinions of authors expressed herein do not necessarily state or reflect those of the United States Government or any agency thereof. 
Reactor and Nuclear Systems Division

\title{
ADVANCED SMALL MODULAR REACTOR ECONOMICS STATUS REPORT
}

\author{
T. Jay Harrison
}

Date Published: October 2014

Prepared by

OAK RIDGE NATIONAL LABORATORY

Oak Ridge, Tennessee 37831-6283

managed by

UT-BATTELLE, LLC

for the

US DEPARTMENT OF ENERGY

under contract DE-AC05-00OR22725 



\section{CONTENTS}

Page

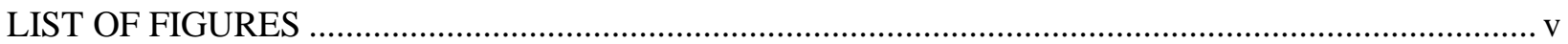

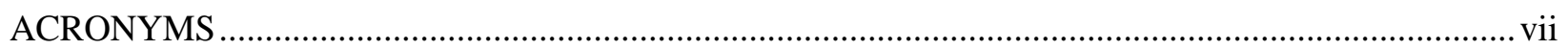

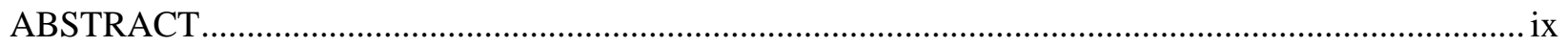

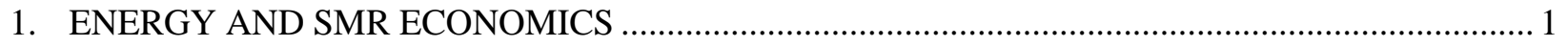

2. ADVANCED REACTOR AND FUEL CYCLE COST ESTIMATES …........................................... 5

3. POTENTIAL ISSUES IN MARKET AND TECHNOLOGY PREDICTION .................................. 7

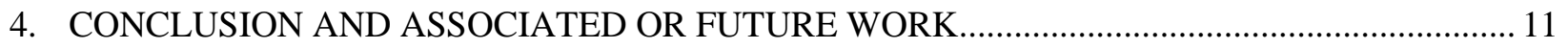

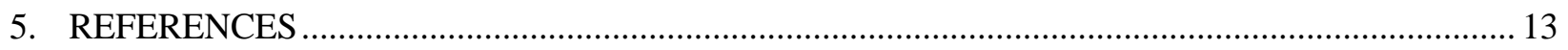





\section{LIST OF FIGURES}

Figure $\quad$ Page

1. Selected wholesale electricity and natural gas price hubs (EIA data from the

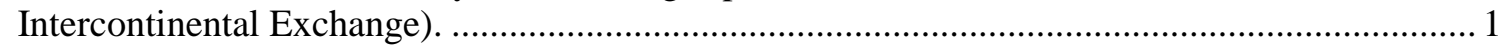

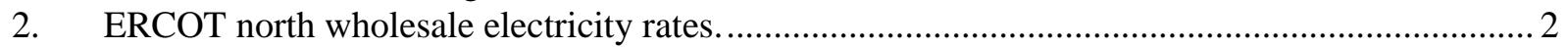

3. Negative Northwest off-peak electricity daily pricing example (2001)...................................... 3

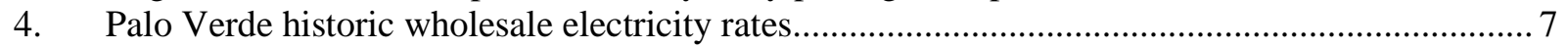

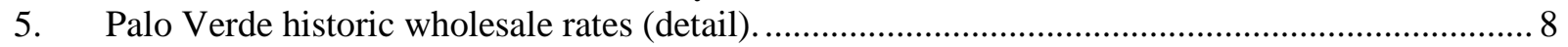

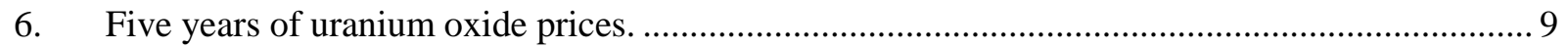





\section{ACRONYMS}

AdvSMR advanced small modular reactor

EIA US Energy Information Administration

ERCOT Electric Reliability Council of Texas

ISO independent system operator

LWR light water reactor

MWeh megawatt electrical hour

ORNL Oak Ridge National Laboratory

PESS

Planning and Economic Studies Section

RTO Regional Transmission Organization

SMR small modular reactor 



\begin{abstract}
This report describes the data collection work performed for an advanced small modular reactor (AdvSMR) economics analysis activity at the Oak Ridge National Laboratory. The methodology development and analytical results are described in separate, stand-alone documents as listed in the references.

The economics analysis effort for the AdvSMR program combines the technical and fuel cycle aspects of advanced (non-light water reactor [LWR]) reactors with the market and production aspects of SMRs. This requires the collection, analysis, and synthesis of multiple unrelated and potentially high-uncertainty data sets from a wide range of data sources. Further, the nature of both economic and nuclear technology analysis requires at least a minor attempt at prediction and prognostication, and the far-term horizon for deployment of advanced nuclear systems introduces more uncertainty.

Energy market uncertainty, especially the electricity market, is the result of the integration of commodity prices, demand fluctuation, and generation competition, as easily seen in deregulated markets. Depending on current or projected values for any of these factors, the economic attractiveness of any power plant construction project can change yearly or quarterly. For long-lead construction projects such as nuclear power plants, this uncertainty generates an implied and inherent risk for potential nuclear power plant owners and operators.

The uncertainty in nuclear reactor and fuel cycle costs is in some respects better understood and quantified than the energy market uncertainty. The LWR-based fuel cycle has a long commercial history to use as its basis for cost estimation, and the current activities in LWR construction provide a reliable baseline for estimates for similar efforts. However, for advanced systems, the estimates and their associated uncertainties are based on forward-looking assumptions for performance after the system has been built and has achieved commercial operation. Advanced fuel materials and fabrication costs have large uncertainties based on complexities of operation, such as contact-handled fuel fabrication versus remote handling, or commodity availability.

Thus, this analytical work makes a good faith effort to quantify uncertainties and provide qualifiers, caveats, and explanations for the sources of these uncertainties. The overall result is that this work assembles the necessary information and establishes the foundation for future analyses using more precise data as nuclear technology advances.
\end{abstract}





\section{ENERGY AND SMR ECONOMICS}

The economic analysis of advanced small modular reactors (AdvSMRs) first requires an understanding of the current energy market, the current gigawatt-class nuclear prospects (such as AP-1000) in that energy market, and the future prospects for SMRs in the emerging energy market. The analysis is focused on the electricity market since all current commercial power in the US is used for wholesale electricity generation. Future markets may expand to include process heat for industrial purposes.

The primary data source for the electricity market side of energy economics is the Energy Information Administration (EIA). The EIA tracks the retail electricity rates by state or geographic division and by end-use sector, and information from January 2001 to the present is easily accessible via a graphical user interface [Ref. 1].

However, the most important value to consider for electricity generation is the wholesale rate in deregulated markets. This is what generators will receive for the power they generate based on a competitive bid basis that includes competition from all other generation types. The EIA also has that data, but these data are not as complete or thorough. The EIA's data come from the Intercontinental Exchange, which publishes information from several selected price hubs [Ref. 2]. Fig. 1 shows the price hubs and their regional transmission organizations (RTOs) or independent system operators (ISOs).

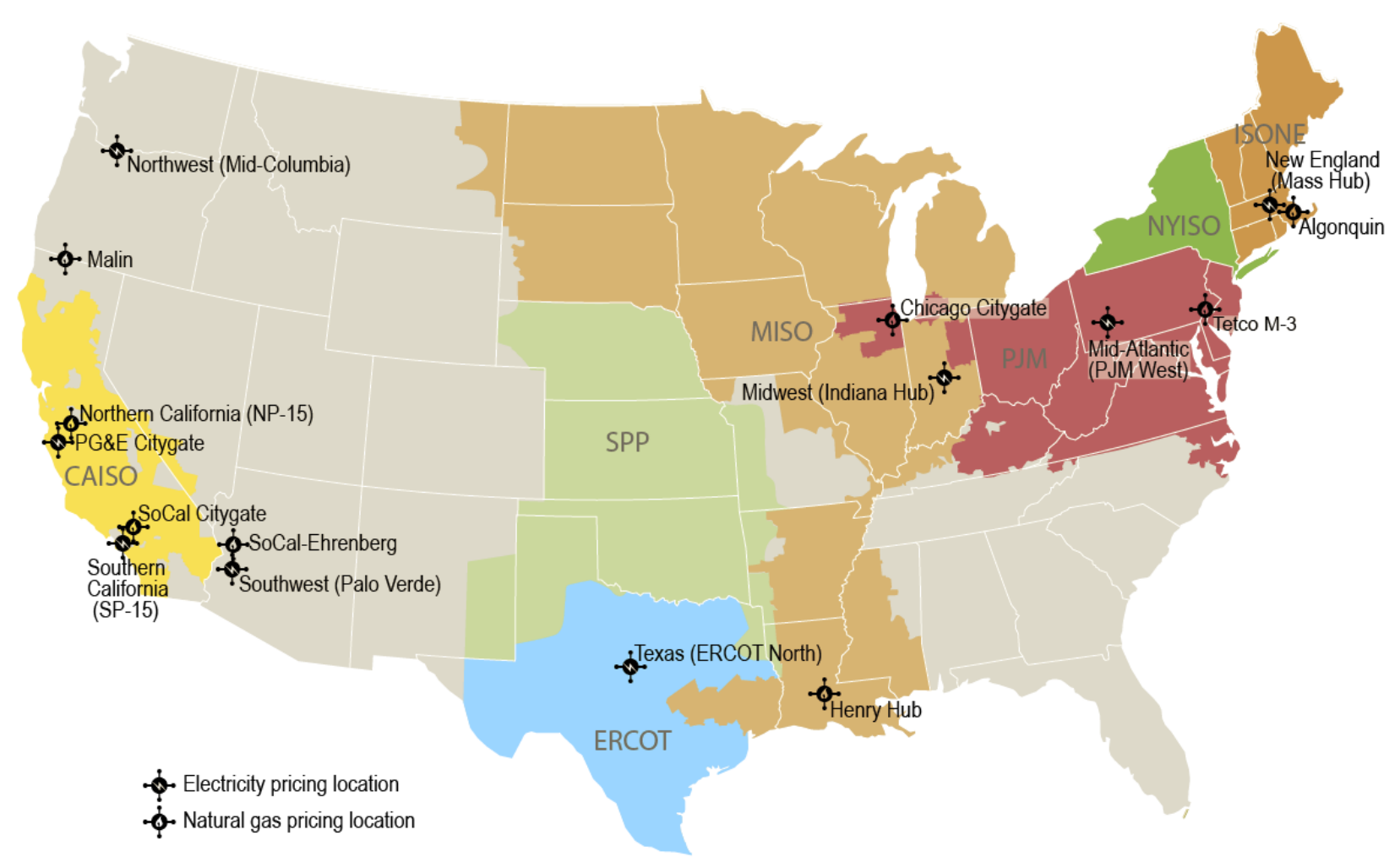

Note: Colored areas denote Regional Transmission Organizations (RTO)/Independent System Operators (ISO)

Source: U.S. Energy Information Administration based on Ventyx Energy Velocity Suite

Fig. 1. Selected wholesale electricity and natural gas price hubs

(EIA data from the Intercontinental Exchange). 
The daily electricity rates in dollars per megawatt hour (\$/MWeh) for the Electric Reliability Council of Texas (ERCOT) north hub are shown in Fig. 2. Note that "MWeh" and "MWh" are used interchangeably.

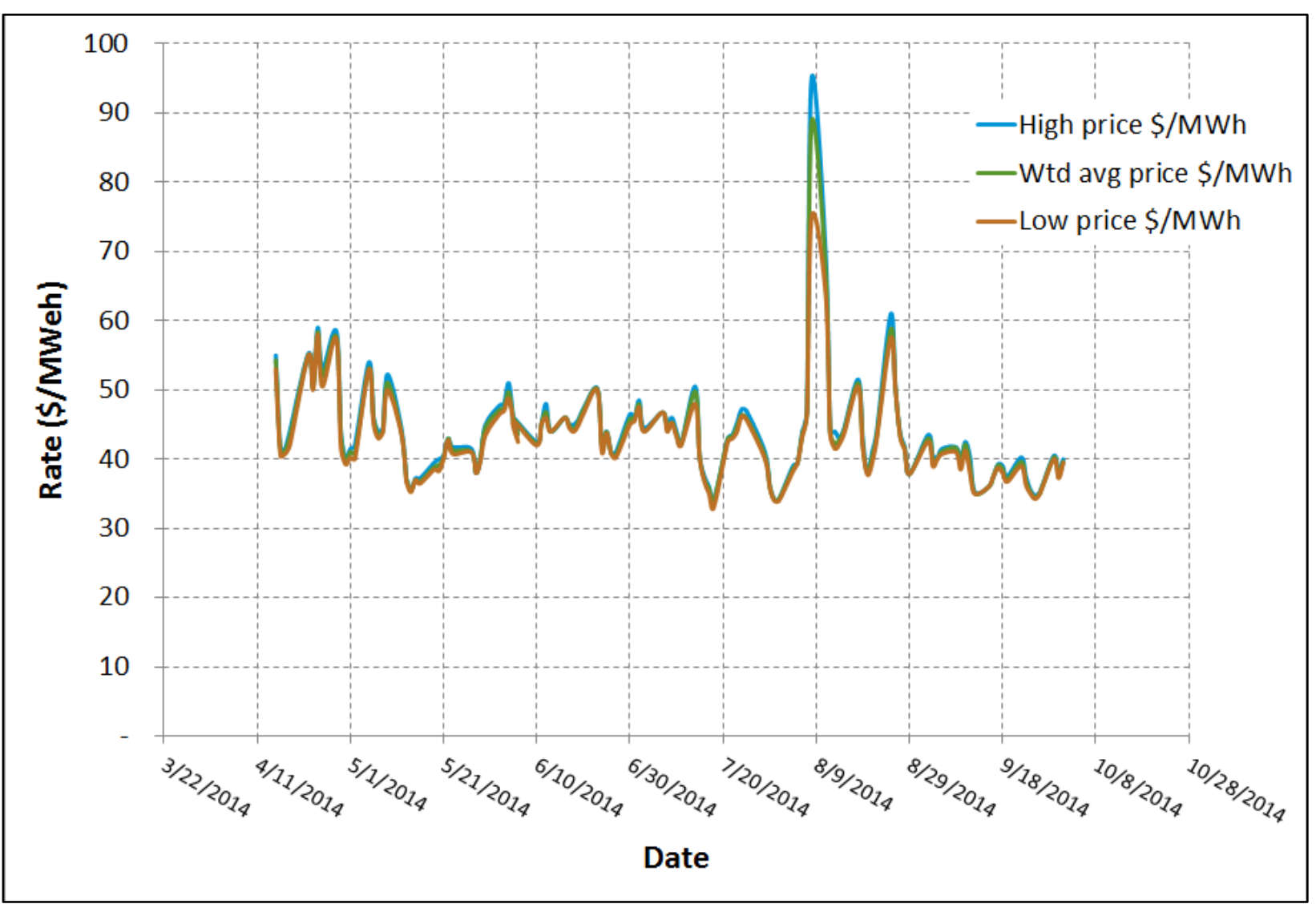

Fig. 2. ERCOT north wholesale electricity rates.

As Fig. 2 shows, the wholesale rates in the ERCOT north hub during the summer of 2014 were typically in the range of $\$ 40 / \mathrm{MWeh}$ except during a brief period in which the rate peaked near \$90/MWeh. Thus, for the ERCOT market in the summer of 2014, a typical wholesale rate of \$40/MWeh could be assumed for analytical purposes. The assumption methodology discussed here will be re-examined in Sect. 3.

The areas in Fig. 1 that do not have an RTO or ISO, such as the Southeastern US, are regulated markets. In these markets, the different generators, including the nuclear power plants, do not compete on an open market. Thus, while there are still variations in the demand that must be met by bringing high-cost peaking plants online, the overall wholesale rate is not subject to competitive bids.

Wholesale rates in RTOs and ISOs vary due to the nature of the competitive bid process. This process uses the current and expected demand to call for power supplies, and power generators competitively bid to be chosen to supply power to the system. At times of low demand, the low-cost baseload generators such as nuclear and coal can cover the full load and win the bid process with low bids. At times of high demand, the baseload generators cannot cover the full demand, and peaking producers such as natural gas come online. When these higher-cost peaking plants come online, they raise the total bid price as a natural response to market demands.

When incorporating subsidized power sources, the bid process sometimes experience brief periods of negative electricity prices [Ref. 3]. For example, during overnight weekend hours in temperate but sufficiently windy weather, the demand for electricity can drop and the wind power supply can increase. 
In this case, the significant fraction of demand can be met by wind power, pushing the total bid price into negative territory. Fig. 3 shows an example of negative pricing data [Ref. 4].

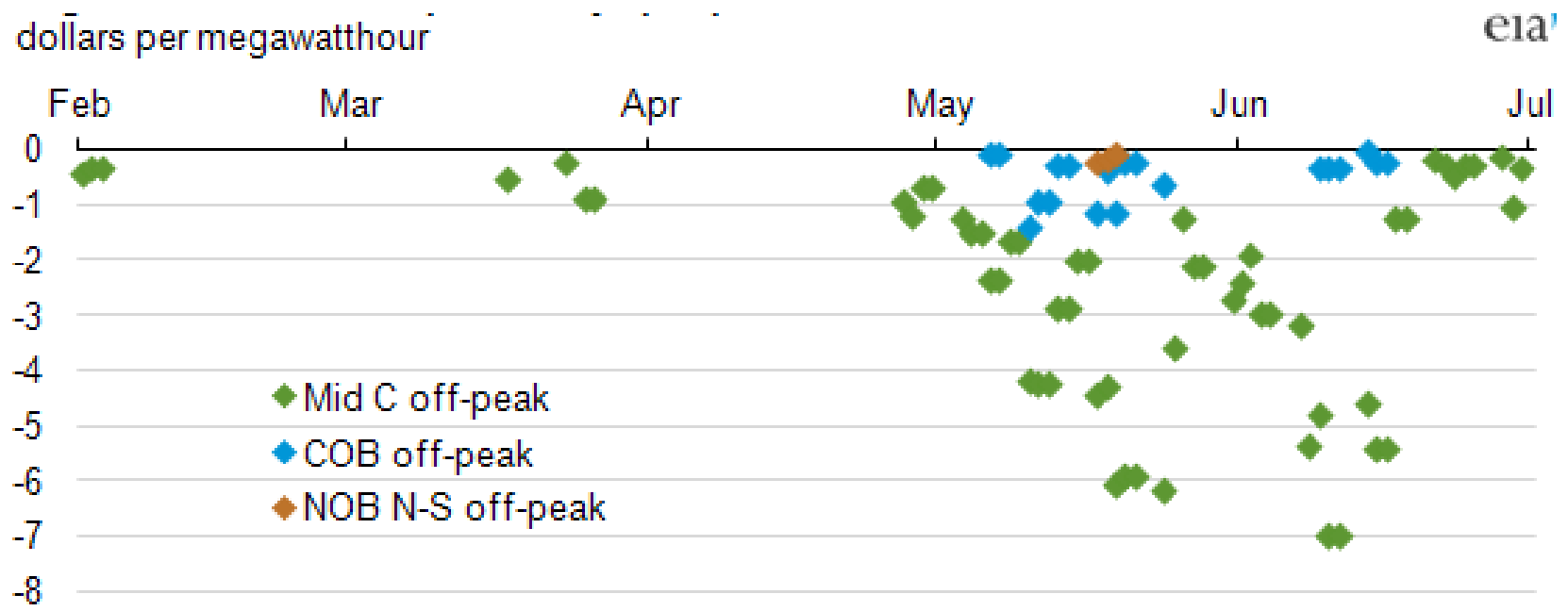

Fig. 3. Negative Northwest off-peak electricity daily pricing example (2001). 



\section{ADVANCED REACTOR AND FUEL CYCLE COST ESTIMATES}

The next step in the economics analysis uses advanced reactor cost estimates in lieu of LWR-based cost estimates. A straightforward analysis of the overall costs shows that the main driver is the capital cost; likewise, the main driver in the total cost uncertainty is the capital cost uncertainty. Advanced fuel cycle facilities, services, and commodities also have appreciable uncertainty associated, but one of the chief characteristics of advanced reactors is a more efficient use of the fuel material. For fuel cycles with very high burnup, the higher-cost and higher-uncertainty fuel cycle costs can be offset by lesser throughput. This higher fuel efficiency tends to lessen the overall cost dependence on the fuel cycle.

The primary data source for the advanced reactor and fuel cycle cost estimates is the Advanced Fuel Cycle Cost Basis [Ref. 5]. This report, updated and published periodically by Idaho National Laboratory for the US Department of Energy, collects and curates cost information for all aspects of the nuclear fuel cycle. The information is derived from domestic and international industry, academia, and government sources and includes market cost information for the current LWR-based fuel cycle, as well as estimates for advanced fuel cycle commodities and services. The most recent version of this report was released in 2009. An updated addendum is expected to be released in 2014.

Other sources of nuclear power cost data include:

- the US Energy Information Administration (cost data is based on LWR-based technology [Ref. 6]);

- the Organisation for Economic Co-operation and Development Nuclear Energy Agency [Ref. 7]; and

- $\quad$ the International Atomic Energy Agency [Ref. 8]. 



\section{POTENTIAL ISSUES IN MARKET AND TECHNOLOGY PREDICTION}

There are many potential issues that impact predicting or forecasting future markets or technological development. While typical business planning has development cycles measured in quarters or years, the nature of advanced reactor planning requires a horizon of decades.

Predicting the future of electricity markets is challenging. One method is to use historic rates as a baseline by tracking the RTO markets. The EIA tracks the wholesale electricity rates in the Southwest through the Palo Verde RTO hub located in Maricopa County, Arizona. The historical wholesale rates for the Palo Verde hub from January 2001-April 2014 are shown in Fig. 4.

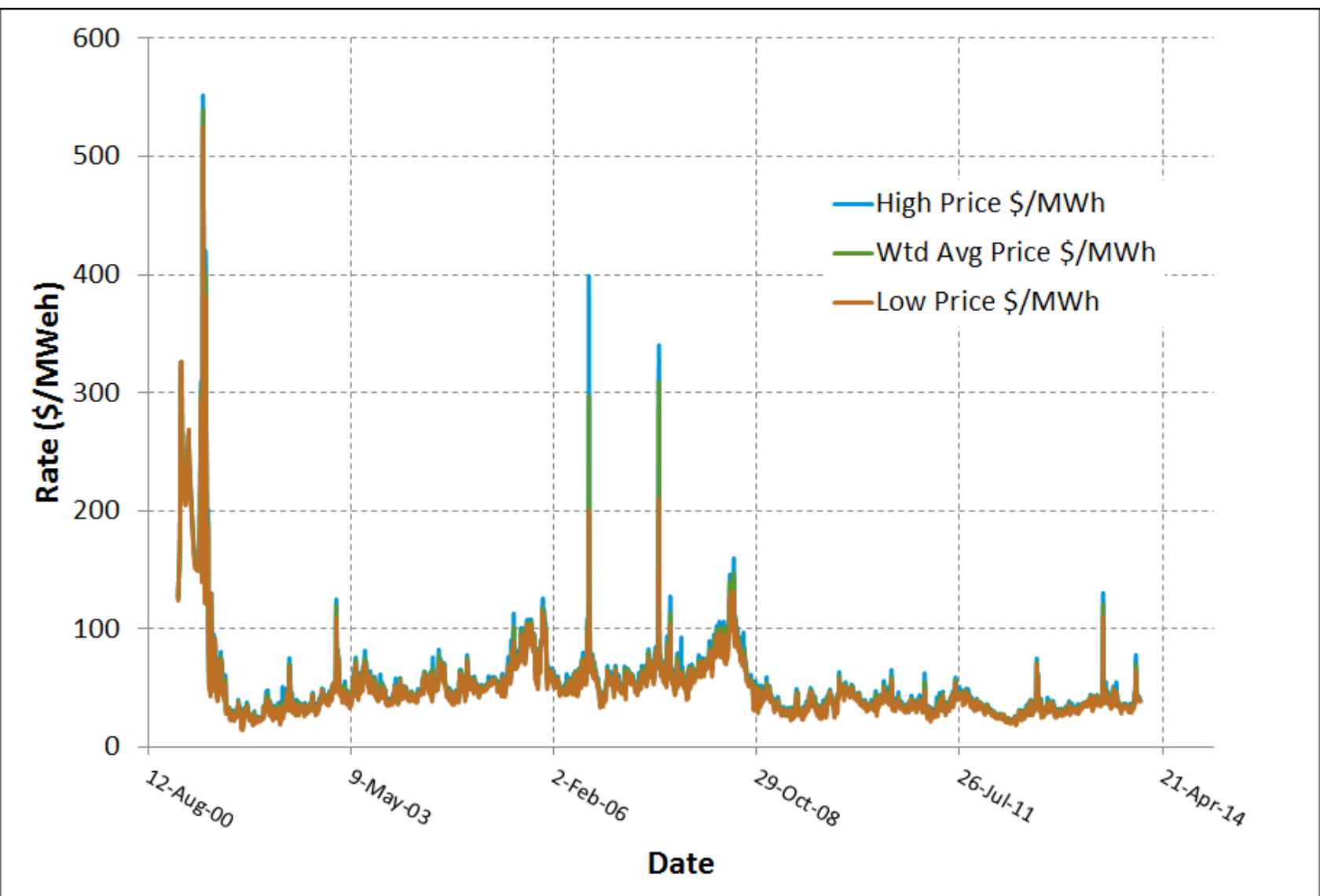

Fig. 4. Palo Verde historic wholesale electricity rates.

In 2001, 2006, and 2007, the Palo Verde wholesale electricity rates spiked ${ }^{1}$ to more than $\$ 300 / \mathrm{MWeh}$. However, the vast majority of rates for Palo Verde electricity during this time were less than \$100/MWeh. A close-up depiction of the rate is shown in Fig. 5.

\footnotetext{
${ }^{1}$ Spikes like these typically occur when low-cost power sources, such as baseload coal or nuclear plants, go offline unexpectedly. Another cause would be a sudden unexpected increase in demand during planned baseload outages, such as a sudden cold front increasing demand for heating. Either scenario requires multiple high-cost peaking sources to come online on short notice.
} 


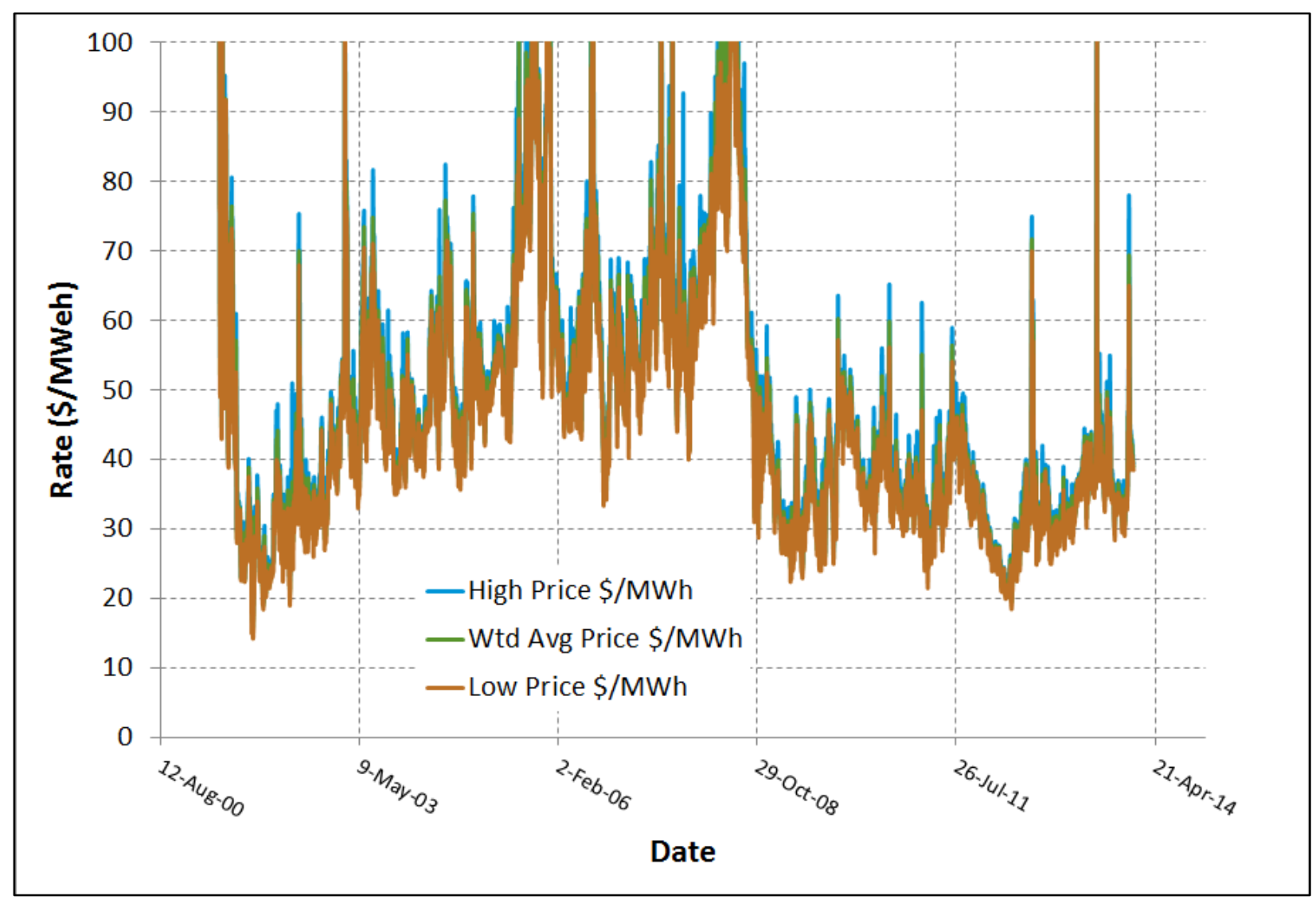

Fig. 5. Palo Verde historic wholesale rates (detail).

Judging from the steady rate climb of the Palo Verde wholesale rates from 2001 through 2007, a longterm average of \$65/MWeh to \$70/MWeh would be justified for future analyses and may be even considered a conservative estimate. However, the economic downturn in 2007 led to a much lower demand for power, which in turn led to lower energy prices. The average rate from 2007 to the present at this hub is on the order of \$35/MWeh, with an occasional spike above \$100/MWeh.

The economic performance of a nuclear power plant is directly tied to the difference between its operating cost and the rate at which it can sell its power. The EIA estimates the cost of new nuclear construction at around \$96/MWeh before any applied subsidy [Ref. 2]. Figure 2 shows that the wholesale rates for the Palo Verde hub were approaching \$96/MWeh in 2005 and again in 2007. However, assume that new nuclear construction was started in 2006 with an expected economic performance based on that recent history. If construction had been completed in 2010 (for example), it would have gone into a competitive market where it would operate at a loss.

Nuclear power cost estimates are impacted by similar issues. The cost of nuclear fuel is based on the cost of a commodity (uranium) and services (enrichment and fabrication). Assuming that the fabrication cost is fairly constant (or at least slowly varying), then the uranium and enrichment costs are functions of uranium supply and enrichment facility availability. Fig. 6 shows the uranium price over the last five years [Ref. 9]. 


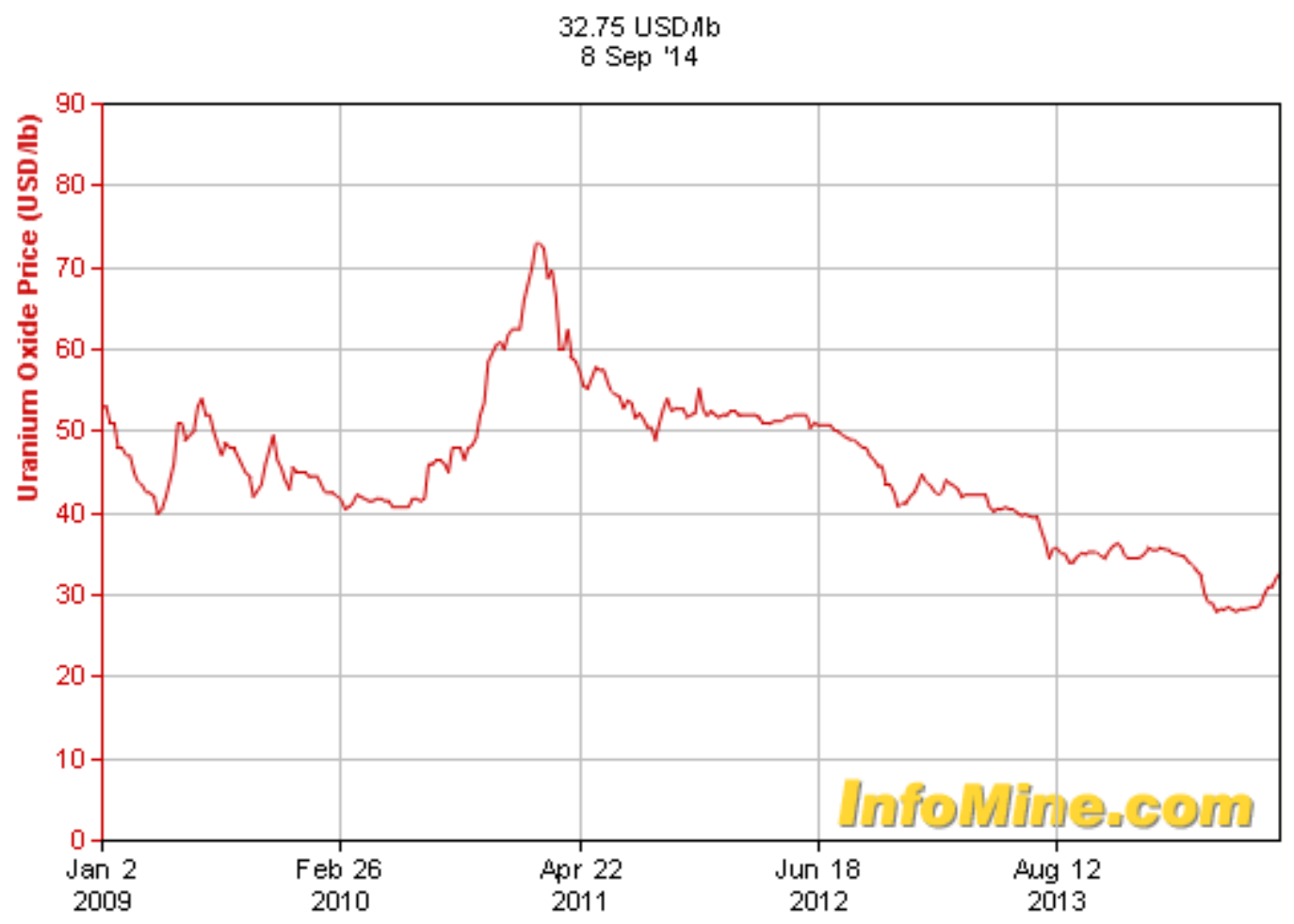

Fig. 6. Five years of uranium oxide prices.

Fig. 6 shows a factor of two fluctuations over this time period, and historic prices show even greater fluctuations for both uranium and enrichment [Ref. 5]. Thus, forecasting both the cost of nuclear power and the market conditions in which it must compete carries a large degree of uncertainty. 



\section{CONCLUSION AND ASSOCIATED OR FUTURE WORK}

Economic analysis of advanced nuclear systems requires an understanding of current nuclear power economics. While there are multiple data sources for historic and current market factors, the main factor to consider in determining the feasibility of building and operating a nuclear power plant is the uncertainty in the market conditions. Uncertainty in any analysis is expected, but short-term uncertainty in long-term projections_-especially uncertainty of profitability_invariably makes a long-term project less attractive.

Associated work on nuclear economics has incorporated uncertainty analysis for the levelized power production cost [Ref. 10], but there is no way to predict market conditions. Other associated research has focused on defining what factors may affect the electricity market beneficially for nuclear power [Ref. 11].

Future work will analyze non-electricity markets and will track and refine advanced reactor and fuel cycle cost estimates. 



\section{REFERENCES}

1. U.S. Energy Information Administration, Electricity Data Browser, http://www.eia.gov/electricity/data/browser/\#/topic/7?agg=2,0,1\&geo=g\&freq= M\&start=200101\&end=201405\&ctype=linechart\&ltype=pin\&rtype=s\&maptype=0\&rse=0\&pin=, accessed 10/3/2014.

2. U.S. Energy Information Administration, Wholesale Electricity and Natural Gas Market Data, http://www.eia.gov/electricity/wholesale/index.cfm, accessed 10/3/2014.

3. Bloomberg, Nuclear Industry Withers in U.S. as Wind Pummels Prices, http://www.bloomberg.com/news/2013-03-11/nuclear-industry-withers-in-u-s-as-wind-pummelsprices-energy.html, accessed 10/3/2014.

4. U.S. Energy Information Administration, Today in Energy, http://www.eia.gov/todayinenergy/detail.cfm?id=5110, accessed 10/9/2014.

5. D. Shropshire, et al, Advanced Fuel Cycle Cost Basis, INL/EXT-07-12107, Rev.2, Idaho National Laboratory, Idaho Falls, ID, April 2009.

6. U.S. Energy Information Administration, Annual Energy Outlook 2014, http://www.eia.gov/forecasts/aeo/electricity generation.cfm, accessed 10/3/2014.

7. Organisation for Economic Co-operation and Development Nuclear Energy Agency, http://www.oecd-nea.org/press/press-kits/economics.htm, accessed 10/3/2014.

8. International Atomic Energy Agency, Planning and Economic Studies Section (PESS) Capacity Building Sustainable Energy Development PESS Publication, http://www.iaea.org/OurWork/ST/NE/Pess/publications.html, accessed 10/3/2014.

9. InfoMine, 5 Year Uranium Prices and Price Chart, http://www.infomine.com/investment/metalprices/uranium-oxide/5-year/, accessed 9/15/2014.

10. T. Jay Harrison, “Advanced Small Modular Reactor Economics Model Development”, ORNL/LTR2014/516, Oak Ridge National Laboratory, Oak Ridge, TN, October 2014.

11. T. Jay Harrison, "Economic Conditions and Factors Affecting New Nuclear Power Development", ORNL/LTR-2014/560, Oak Ridge National Laboratory, Oak Ridge, TN, October 2014. 